\title{
ATIVIDAde CELULOLÍTICA DE LEVEdURAS ISOLAdAS \\ DE FRUTOS DE PALMEIRAS
}

\author{
EDUARDO HENRIQUE SANTOS GUEDES* \\ DANIELLA TAVARES DE ALMEIDA* \\ THIAGO LUCAS DE ABREU-LIMA*** \\ SOLANGE CRISTINA CARREIRO ${ }^{* * * *}$
}

\begin{abstract}
O trabalho avaliou a capacidade celulolítica de 150 linhagens de leveduras isoladas dos frutos das palmeiras Inajá, Buriti, Tucum e Macaúba. A seleção de linhagens celulolíticas foi feita em meio sólido contendo carboximetilcelulose (CMC), onde foram inoculadas oito linhagens por placa e incubadas por sete dias a 25,35 e $40^{\circ} \mathrm{C}$. Os resultados foram expressos em Índice Enzimático (IE), que é a relação entre o diâmetro do halo de hidrólise e o diâmetro de crescimento da colônia. Foi observada atividade celulolítica em seis linhagens a $25^{\circ} \mathrm{C}$, quatro linhagens a $35^{\circ} \mathrm{C}$ e duas linhagens a $40^{\circ} \mathrm{C}$. Os valores de IE variaram de 1,60 a 5,25 , sendo que os maiores valores foram obtidos a $40^{\circ} \mathrm{C}$ nas linhagens 11236 e T194, isoladas de Inajá e Tucum, respectivamente. A atividade celulolítica das duas linhagens foi avaliada em cultivo submerso em meio contendo $2 \%$ de CMC, após 72 horas de incubação a $40^{\circ} \mathrm{C}$. A produção de endoglucanases (CMCase) e celulase total (FPase) foi de 0,0436 U. $\mathrm{mL}^{-1}$ de Fpase e 0,380 U. $\mathrm{mL}^{-1}$ de CMCase para a linhagem I1236 e de 0,102 U. $\mathrm{mL}^{-1}$ de FPase e 0,454 de CMCase para a linhagem T194, respectivamente.
\end{abstract}

PALAVRAS-CHAVE: ENZIMAS, HIDROLASES, CELULASES, CERRADO, COCOS.

*Engenheiro de Alimentos, Universidade Federal do Tocantins, edu3-d@hotmail.com "Engenheira de Alimentos, Universidade Federal do Tocantins, danistavares0@gmail.com

**Doutor em Biotecnologia, Universidade Federal do Tocantins, abreulimtl@uft.edu.br

****Doutora em Microbiologia Aplicada, Universidade Federal do Tocantins, solange@uft.edu.br 


\section{INTRODUÇÃO}

Os estudos envolvendo as enzimas de origem microbiana é objetivo de muitas pesquisas, pois apresenta vantagens em relação às de origem vegetal ou animal. A diversidade de microrganismos existentes que possam ser utilizados para produção enzimática é grande, e há possibilidade de se identificar novas espécies para esse fim. Assim, é importante o isolamento e estudo de leveduras selvagens, em especial a análise de seus perfis de produção enzimática. Resende (2014) reporta a importância do sinergismo entre microrganismos e plantas, enfatizando que essa interação envolve uma série de fatores, entre eles a produção de substâncias químicas diversas por ambos os organismos, como, por exemplo, enzimas e outras moléculas biologicamente ativas.

As leveduras são encontradas naturalmente em frutos ou em substratos com grande disponibilidade de matéria orgânica, especialmente açúcares. Devido à produção de compostos de interesse industrial, como na produção de alimentos, enzimas, biocombustíveis, entre outros, as leveduras apresentam importância econômica, sendo utilizadas por diversos setores comerciais. O sucesso do uso de leveduras no setor industrial está relacionado à habilidade de se adaptarem e resistirem a condições de estresse, à ausência do efeito da sazonalidade, à facilidade na manipulação genética e rápido desenvolvimento da cultura (MATTANOVICH et al., 2014; ZYMANCZYK-DUA et al., 2017).

Novos estudos têm tido um efeito significativo no aumento de enzimas para o uso em diversos processamentos com o objetivo de reduzir os custos, aumentar a produção de extratos de matérias-primas e melhorar a manipulação de materiais, a vida de prateleira e as características sensoriais de alimentos (ZHANG et al., 2018).

Os estudos permitem a obtenção de linhagens microbianas produtoras de enzimas extracelulares com potencial de uso industrial, sendo que as enzimas hidrolíticas, como lípases, proteases, celulases, xilanases e amilases, têm se destacado (RESENDE, 2014). As celulases têm aplicação nas indústrias de alimentos, têxtil, bebidas, detergentes, bicombustíveis de segunda geração, cosméticos e fármacos, além de outras aplicações, como na clarificação de sucos de frutas, melhoramento de produtos de panificação, polimento e lavagem de têxteis e biorremediação (ADRIO e DEMAIN, 2014; BEBERA et al., 2017).

As celulases são classificadas como hidrolases capazes de hidrolisar as ligações glicosídicas da celulose. A celulose é o componente fundamental dos materiais de origem vegetal ou ligocelulósicos, é um polímero composto por unidades de D-glicose unidas por ligações $\beta-1,4$ glicosídicas (BEBERA et al., 2017). As celulases atuam na hidrólise da celulose a partir de três grupos de enzimas: as endoglucanases, que hidrolisam aleatoriamente as ligações $\beta-1,4$ glicosídicas, as exoglucanases, que liberam celobiose, e as $\beta$-glicosidades, que hidrolisam a celobiose liberando glicose (FLORENCIO et al., 2017).

As enzimas celulases são produzidas especialmente por fungos filamentosos e bactérias (RAVINDRAN e JAISWAL, 2017), porém alguns estudos têm demonstrado o potencial de leveduras para produção dessas enzimas, sendo isoladas de frutos da cagaita (Eugenia dysenterica) (COELHO, 2016), do solo de diferentes regiões do cerrado brasileiro (CARVALHO, 2013) ou leveduras geneticamente modificadas (INOKUMA et al., 2014) o que torna importante a exploração da biodiversidade desses micro-organismos, podendo levar à descoberta de novas linhagens para esse fim.

Os frutos de palmeiras do cerrado Tocantinense têm sido utilizados em diversos estudos envolvendo a qualidade nutricional e o desenvolvimento de novos produtos alimentícios. Entretanto pouca atenção tem sido dada à diversidade e ao papel da microbiota de leveduras associada a esses frutos, o que é fundamental aos estudos de bioprospecção de micro-organismos. Portanto, este trabalho teve como objetivo avaliar a capacidade de produção de celulases por leveduras isoladas dos frutos das palmeiras Inajá, Buriti, Tucum e Macaúba. 


\section{MATERIAL E MÉTODOS}

\subsection{LINHAGENS DE LEVEDURAS}

Foram utilizadas neste trabalho 150 linhagens de leveduras previamente isoladas dos frutos das palmeiras, Inajá (Maximiliana maripa), Buriti (Mauritia flexuosa), Tucum (Bactris setosa) e Macaúba (Acrocomia aculeata). Todas as linhagens pertencem à coleção de culturas Carlos Rosa da Universidade Federal do Tocantins e estão preservadas a $-80^{\circ} \mathrm{C}$.

Antes de realizar os experimentos, todas as linhagens foram reativadas em ágar Sabouraudglicose pela técnica de estriamento. As placas foram incubadas a $28^{\circ} \mathrm{C}$ por 48 horas.

\subsection{PRODUÇÃO DE ENZIMAS EM MEIO SÓLIDO E SELEÇÃO DE LINHAGENS CELULOLÍ- TICAS}

A capacidade celulolítica das linhagens foi avaliada em meio sólido contendo carboximetilcelulose - CMC $\left(0,5 \mathrm{~g} \cdot \mathrm{L}^{-1}\right)$, glicose $\left(2 \mathrm{~g} \cdot \mathrm{L}^{-1}\right)$, peptona $\left(2 \mathrm{~g} \cdot \mathrm{L}^{-1}\right)$, extrato de levedura (1 g. $\left.\mathrm{L}^{-1}\right)$ e ágar $\left(1,8 \mathrm{~g} \cdot \mathrm{L}^{-1}\right)$. Foram inoculadas oito linhagens por placa com o uso de palitos de dente estéreis e as placas foram incubadas durante sete dias a $25^{\circ} \mathrm{C}, 35^{\circ} \mathrm{C}$ e $40^{\circ} \mathrm{C}$. Após o período de incubação as placas foram tratadas com vapor de iodo para a revelação os halos de hidrólise segundo a metodologia de Kasana (2008). Os diâmetros dos halos de hidrólise $(\mathrm{H})$ e do crescimento das colônias $(C)$ foram aferidos com auxílio de paquímetro e os resultados foram dados como o Índice Enzimático (IE), que é a relação H/C, segundo proposto por Hankin e Anagnostakis (1975).

Os experimentos foram realizados em três repetições e o delineamento experimental foi em blocos inteiramente casualizados. Os dados foram analisados por meio da análise de variância (Anova) e teste de Tukey ao nível de $5 \%$ de significância para a comparação de médias usando o programa ASSISTAT 7.7 beta.

\subsection{PRODUÇÃO DE CELULASE EM CULTIVO SUBMERSO}

Com base nos resultados obtidos para os valores de IE, foram selecionadas as duas linhagens para a quantificação das celulases produzidas utilizando cultivo submerso.

As duas linhagens selecionadas foram inoculadas em caldo Sabouraud ( $5 \mathrm{~g} . \mathrm{L}^{-1}$ de extrato de levedura, $30 \mathrm{~g} \cdot \mathrm{L}^{-1}$ de glicose, $10 \mathrm{g.L} \mathrm{L}^{-1}$ de peptona) e incubadas por 18 horas a $28^{\circ} \mathrm{C}$ com agitação de 150 rpm, para obtenção do inoculo. Logo após o tempo de incubação as células foram separadas por centrifugação a 5000 rpm por 60 minutos e ressuspendidas em água destilada estéril. Volumes adequados dessa suspensão foram utilizados para inocular o meio para produção de celulase de modo a se obter concentração inicial de $10^{8}$ células. $\mathrm{mL}^{-1}$. A produção de celulase foi feita em meio contendo $5 \mathrm{~g} . \mathrm{L}^{-1}$ de CMC, $10 \mathrm{~g} . \mathrm{L}^{-1}$ de peptona, $5 \mathrm{~g} . \mathrm{L}^{-1}$ de extrato de levedura. Os frascos foram incubados por 72 horas a $40^{\circ} \mathrm{C}$ com agitação de $100 \mathrm{rpm}$. Alíquotas de $10 \mathrm{~mL}$ foram colhidas a cada 24 horas, centrifugadas durante uma hora, e o sobrenadante obtido (extrato enzimático bruto - EEB) foi utilizado para quantificação da atividade celulolítica. Os experimentos foram realizados em três repetições.

\subsection{DETERMINAÇÃO DA ATIVIDADE CELULOLÍTICA}

Foram quantificadas as atividades de endoglucanases (CMCase) e celulose total (FPase), segundo metodologia proposta por Ghose (1987). Para CMCase, o meio reacional foi composto por $1 \mathrm{~mL}$ de EEB e $1 \mathrm{~mL}$ de solução CMC $\left(2{\mathrm{~g} . \mathrm{L}^{-1}}^{-1}\right)$ em tampão citrato $0,05 \mathrm{~mol}^{\mathrm{L}} \mathrm{L}^{-1} \mathrm{pH}$ 5,0. Para 
FPase, o meio reacional foi composto por uma tira de papel filtro Whatman $\mathrm{n}^{\circ} 1$ de $1 \times 6 \mathrm{~cm}$ e $1 \mathrm{~mL}$ do mesmo tampão. A reação ocorreu a $40^{\circ} \mathrm{C}$, durante 30 minutos e as atividades celulolíticas foram quantificadas a partir da dosagem de açúcares redutores (AR) liberados, utilizando-se o método do DNS - ácido 3,5 dinitrosalisílico (MILLER, 1959). Uma unidade de atividade de celulolítica (U.mL1) foi considerada como a quantidade de enzima capaz de produzir $1 \mu \mathrm{mol}$ de açúcar redutor por $\mathrm{mL}$ por minuto de reação. Foram utilizados controles da reação colorimétrica para descontar as contribuições do extrato enzimático bruto (branco da enzima) e do substrato (branco da reação), separadamente, dos valores de absorbância obtidos.

\section{RESULTADOS E DISCUSSSÃO}

\subsection{SELEÇÃO DE LINHAGENS CELULOLÍTICAS}

Dentre as 150 linhagens estudadas, obteve-se resultados positivos em todas as temperaturas estudadas, sendo seis linhagens $(4 \%)$ positivas a $25^{\circ} \mathrm{C}$, quatro linhagens $(2,66 \%)$ a $35^{\circ} \mathrm{C}$ e duas linhagens $(1,33 \%)$ a $40^{\circ} \mathrm{C}$ (tabela 1). Somente as linhagens isoladas de Inajá e Tucum apresentaram resultados positivos. Os valores de IE variaram de 1,6 a 5,25 e são tidos como bons indicativos de atividade enzimática, salientando que o maior índice enzimático foi da linhagem I1236 a $40^{\circ} \mathrm{C}$ isolada do fruto de Inajá. Observou-se a diminuição na quantidade de linhagens produtoras de celulase com o aumento da temperatura de incubação.

TABELA 1: VALORES MÉDIOS DOS ÍNDICES ENZIMÁTICOS (IE) PARA A PRODUÇÃO DE CELULASE NAS DIFERENTES TEMPERATURAS

\begin{tabular}{|c|c|c|c|}
\hline Linhagem & $25^{\circ} \mathrm{C}$ & $35^{\circ} \mathrm{C}$ & $40^{\circ} \mathrm{C}$ \\
\hline T15 & $1,60^{b}$ & $2,40^{b}$ & - \\
\hline T17 & $1,85^{\mathrm{ab}}$ & - & - \\
\hline T152 & $2,13^{a b}$ & - & - \\
\hline T194 & $2,69^{\mathrm{ab}}$ & - & $4,25^{a}$ \\
\hline T199 & - & $3,61^{\mathrm{ab}}$ & - \\
\hline T250 & - & $4,09^{a}$ & - \\
\hline 1295 & $2,05^{\mathrm{ab}}$ & - & - \\
\hline |1236 & $2,83^{a}$ & $3,24^{\mathrm{ab}}$ & $5,25^{a}$ \\
\hline
\end{tabular}

$\mathrm{I}=$ Inajá; $\mathrm{T}=$ Tucum; IE = índice enzimático; (-) resultado negativo. Médias seguidas com a mesma letra (coluna) não diferem entre si pelo teste de Tukey $(p<0,05)$. Média de três repetições.

No cultivo a $40^{\circ} \mathrm{C}$ apenas duas leveduras produziram celulases, entretanto a atividade enzimática foi expressivamente maior (tabela 1).

Os resultados encontrados neste trabalho para produção de celulase coincidem com o trabalho de Carvalho (2013), em relação à baixa porcentagem de linhagens produtores dessa enzima. O autor avaliou 307 linhagens de leveduras isoladas do cerrado mineiro para a produção de enzimas celulolíticas e xilanolíticas, encontrando 17 linhagens $(5,5 \%)$ positivas para celulase e seis linhagens $(1,9 \%)$ para xilanase a $28^{\circ} \mathrm{C}$. 
Apesar do baixo percentual de linhagens produtoras de celulase encontradas no nosso estudo, a maioria apresentou valores de índice enzimáticos considerados na literatura como bons indicadores para produção de enzimas, uma vez que índices enzimáticos maiores ou iguais a 2 são considerados satisfatórios para a produção de enzimas em meio sólido como proposto por Lealem e Gashe (1994).

Esse processo de isolamento e seleção de novos micro-organismos produtores de celulase é de grande importância tendo em vista a procura por novas linhagens produtoras de enzimas (KASANA et al., 2008).

\subsection{PRODUÇÃO DE CELULASE EM CULTIVO SUBMERSO}

Uma vez que as linhagens T194 e I1236 apresentaram os maiores valores de IE, ambas foram selecionadas para os testes em cultivo submerso. Os valores de atividade celulolítica encontrados para a linhagem T194 foram de 0,454 U. $\mathrm{mL}^{-1}$ para CMCase e $0,102 \mathrm{U} \cdot \mathrm{mL}^{-1}$ para Fpase. A linhagem 11236 apresentou uma atividade de $0,380 \mathrm{U} \cdot \mathrm{mL}^{-1}$ para CMCase e $0,0436 \mathrm{U} \cdot \mathrm{mL}^{-1}$ para Fpase (tabela 2).

\section{TABELA 2: VALORES DE ATIVIDADE ENZIMÁTICA (U.ML-1) PARA AS LINHAGENS T194 E I1236.}

\begin{tabular}{lcc}
\hline & \multicolumn{2}{c}{ LINHAGENS } \\
\cline { 2 - 3 } CMCase & $0,454(0,183354)$ & 11236 \\
\hline FPase & $0,102(0,014142)$ & $0,380(0,062944)$ \\
\hline
\end{tabular}

Média de três repetições (desvio padrão)

Yanase et al. (2010) estudaram a atividade celulolítica de uma linhagem de Saccharomyces cerevisiae manipulada geneticamente para produzir a enzima CMCase e obtiveram uma atividade de 0,00356 U. $\mathrm{mL}^{-1}$, valor bastante inferior se compararmos com os resultados encontrados para as linhagens do presente estudo.

Coelho (2016) avaliou a produção de CMCase por leveduras isoladas de frutos de cagaita (Eugenia dysenterica) e obteve atividade celulolítica variando de $0,15 \mathrm{U} \cdot \mathrm{mL}^{-1}$ a $0,61 \mathrm{U} \cdot \mathrm{mL}^{-1}$, valores próximos aos encontrados em nosso estudo.

Muitos microrganismos são eficazes na produção de enzimas celulolíticas, entretanto os fungos filamentosos dos gêneros Trichoderma Aspergillus, Penicillium, Fusarium são os mais reportados em estudos para a produção dessas enzimas com destaque para as espécies $T$. reesei e A. niger (SAAD, 2010; FLORENCIO et al., 2017) e poucas pesquisas têm sido realizadas na identificação de leveduras produtoras de celulases.

As leveduras apresentam vantagens como produtoras de enzimas ao serem relacionadas aos fungos filamentosos, como a obtenção de altas concentrações de enzimas por meio da manipulação genética, crescimento rápido em meios simples e de baixo custo e com alta densidade celular, além de apresentarem um reduzido ciclo de fermentação e uma variedade de enzimas catalisadoras da mesma reação, o que viabiliza a versatilidade nas condições de aplicação (ADRIO e DEMAIN, 2014; JOHNSON, 2013; YALÇIN e ÇORBAC, 2013). Assim, a busca por novas linhagens de leveduras produtoras de enzimas torna-se fundamental para essa perspectiva. 


\section{CONCLUSÃO}

Dentre as linhagens isoladas das palmeiras Inajá e Tucum, 5,3\% apresentaram atividade celulolítica nos ensaios em meio sólido. Temperaturas mais elevadas $\left(40^{\circ} \mathrm{C}\right)$ parecem favorecer a produção de celulases para as linhagens estudadas, sugerindo sua potencial aplicação para hidrólise de biomassa lignocelulósica no processo de obtenção de etanol de segunda geração ou em biorrefinarias. Além disso, palmeiras do cerrado tocantinense se mostraram promissoras como alvos de prospecção de microrganismos celulolíticos.

\section{ABSTRACT}

\section{CELLULOLYTIC ACTIVITY OF YEASTS ISOLATED FROM PALM TREES FRUITS}

This work evaluated the cellulolytic activity of 150 yeast strains isolated from the palm fruits Inajá, Butiti, Tucum and Macaúba. The cellulolytic strain selection was carried out in solid state containing carboximethylcellulose $(\mathrm{CMC})$, where it was inoculated eight strains on the surface of the agar and incubated for 7 days at 25,35 and $40^{\circ} \mathrm{C}$. The results were expressed as Enzymatic Indices (E.I.) which represents the average diameter of the degradation halo and the average diameter of the colony growth. Cellulolytic activity was observed in 6 strains at $25^{\circ} \mathrm{C}, 4$ strains at $35^{\circ} \mathrm{C}$ and 2 strains at $40^{\circ} \mathrm{C}$. The E.I. values ranged from 1.6 to 5.25 , and the higher values were observed at $40^{\circ} \mathrm{C}$ for strains 11236 and T194 isolated from Inajá and Tucum, respectivelly. The cellulolytic activity of these two strains was evaluated in submerged culture in a medium containing CMC $2.0 \%$ after 72 $\mathrm{h}$ of incubation at $40^{\circ} \mathrm{C}$. The cellulolytic activity was quantified and it was produced endoglucanases (CMCase) and total cellulases (Fpase), with $0.0436 \mathrm{U} \cdot \mathrm{mL}^{-1}$ of Fpase and $0.380 \mathrm{U} \cdot \mathrm{mL}^{-1}$ of CMCase to strain 11236 and $0.102 \mathrm{U} \cdot \mathrm{mL}^{-1}$ of Fpase and $0.454 \mathrm{U} \cdot \mathrm{mL}^{-1}$ of CMCase to strain T194.

KEY WORDS: ENZYMES; HYDROLASES; CELLULASES; CERRADO; COCONUTS.

\section{REFERÊNCIAS}

1 ADRIO, J. L; DEMAIN, A. L. Microbial enzymes: tools for biotechnological processes. Biomolecules, Tampa, USA, v. 4, p. 117-139, 2014.

2 BEBERA, B.C. et al. Microbial cellulases - Diversity \& biotechnology with reference to mangrove environment: A review. Journal of Genetic Engineering and Biotechnology, v. 15, p. 197-210, 2017.

3 CARVALHO, F. P. Enzimas celulolíticas e xilanolíticas de leveduras isoladas do cerrado mineiro. 2013.118 p. Dissertação (Doutorado em microbiologia agrícola) - Universidade Federal de Lavras, Lavras, 2013.

4 COELHO, S. A. L; ABREU-LIMA, T. L; CARREIRO, S. C. Estudo da atividade celulolítica de uma linhagem de levedura isolada de fruto do cerrado brasileiro. Revista de Química Industrial, s.I. n. 750, p. 56-62, 2016.

5 FLORENCIO, C.; BADINO, A. C.; FARINAS, C. S. Desafios relacionados à produção e aplicação das enzimas celulolíticas na hidrólise da biomassa lignocelulósica. Química Nova, v. 40, n. 9, p. 1082-1093, 2017.

6 GHOSE, T.K. Measurement of cellulase activities. Pure and Applied Chemistry, v.59, p.257268, 1987.

7 HANKIN, L; ANAGNOSTAKIS, S. L. Solid medium containing carboxymethylcellulose to detect Cx cellulase activity of microorganisms. Journal of General Microbiology, s.I. v. 98, n 1 p.109-115, 1975.

8 INOKUMA, K.; HASUNUMA, T.; KONDO, A. Efficient cell-surface display of exo- and endo-cellulase using SED1 anchoring region and its original promoter. Biotechnology for Biofuels, v. 7, n. 1, p. 1-11, 2014.

9 JOHNSON, E. A. Biotechnology of non-Saccharomyces yeasts - the Ascomycetes. Applied Microbiology and Biotechnology, v. 97, p. 503-517, 2013.

10 KASANA C. R. et al. A rapid and easy method for the detection of microbial cellulases on agar plates using Gram's iodine. Current microbiology, New York, v. 57, n. 5, p. 503-507, 2008. 
11 LEALEM, F., GASHE, B. A. Amylase production by a Gram-positive bacterium isolated from fermenting tef (Eraglostis tef). Journal of Applied Bacteriology v.77, p.348-352, 1994.

12 MATTANOVICH, D.; SAUER, M.; GASSER, B. Yeast technology: teaching the old dog new tricks. Microbial Cell Factories, v. 13, n. 34, p. 1-5, 2014.

13 MILLER, G.L. Use of dinitrosalicylic acid reagent for determination of reducing sugar. Analytical Chemistry, v.31, p.426428, 1959.

14 OLIVEIRA, D. T. M. Lipase extracelular de fungo filamentoso: isolamento e caracterização parciais. 2000. $152 \mathrm{f}$. Dissertação (Mestrado em Ciências de Alimentos) - Faculdade de Farmácia da UFMG, Belo Horizonte, 2000.

15 RAVINDRAN, R.; JAISWAL, A. K. Microbial enzyme production using lignocellulosic food industry wastes as feedstock: a review. Bioengineering, v. 3, n. 30, p. 1-22, 2016.

16 RESENDE, A. A. Leveduras associadas a frutos da Macaúba (Acrocomia aculeata (Jaq.) Lodd. ex Mart): diversidade e caracterização quanto à produção de exo-enzimas e fatores de crescimento. 2014.181 f. Dissertação (Mestre em Microbiologia) - Instituto de Ciências Biológicas, Universidade Federal de Minas Gerais, Belo Horizonte, 2014

17 SAAD, M. B. W. Avaliação técnica e econômica preliminar da produção de etanol via hidrólise enzimática de bagaço de cana-de-açúcar. 2010.138 f. Dissertação (Mestre em ciências - Programa de Pós-graduação em Biotecnologia Industrial na área de Conversão de Biomassa) - Escola de Engenharia de Lorena, Universidade de São Paulo, Lorena, 2010.

18 SILVA, E. G. Seleção de leveduras pectinolíticas isoladas de frutas tropicais. 2003. 79 p. Dissertação (Mestrado) Microbiologia Agrícola - Universidade Federal de Lavras, 2003.

19 SILVA, F. A. E. (2004), Assistat versão 7.7 beta. Departamento de Engenharia agrícola do CCT-UFGC, Campina Grande.

20 YALÇIN, H.T.; ÇORBAC, C. Isolation and characterization of amylase producing yeasts and improvement of amylase production. Turkish Journal of Biochemistry, Ankara, Turquia, v. 38, p. 101-108, 2013.

21 YANASE, S. et al. Ethanol production from cellulosic materials using cellulase-expressing yeast. Biotechnology Journal, v. 5, n. 5, p. 449-455, 2010.

22 ZHANG, Y.; HE, S.; SIMPSON, B. K. Enzymes in food bioprocessing - novel food enzymes, applications, and related techniques. Current Opinion in Food Science, v. 19, p. 30-35, 2018.

23 ZYMANCZYK-DUDA, E. et al. Yeast as a versatile tool in biotechnology. In: MORATA, A; LOIRA, I. Yeast. London, UK: IntechOpen, 2017. p. 1-38. 